\title{
L attice V ibrational C haracteristics, Crystal Structure S, and D ielectric P roperties of Li Mn PO 4 Microwave Dielectric Ceramics as a Function of Sintering Temperature
}

\section{xiangyu wang}

Qilu University of Technology

encai xiao

Shandong University of Science and Technology

Lingcui Zhang

Qilu University of Technology

Yue Xu

Qilu University of Technology

tong liu

Qilu University of Technology

Junzhi Yi

Qilu University of Technology

Kaixin Song

Hangzhou Dianzi University

\section{Ze-ming Qi}

USTC: University of Science and Technology of China

feng shi ( $\nabla$ sf751106@sina.com.cn )

Qilu University of Technology https://orcid.org/0000-0003-1043-2838

\section{Research Article}

Keywords: Microwave dielectric ceramics, Lattice vibrational characteristics, Dielectric properties

Posted Date: September 21st, 2021

DOl: https://doi.org/10.21203/rs.3.rs-917436/v1

License: (c) (1) This work is licensed under a Creative Commons Attribution 4.0 International License.

Read Full License 


\section{Lattice Vibrational Characteristics, Crystal Structures, and Dielectric Properties of $\mathrm{LiMnPO}_{4}$ Microwave Dielectric Ceramics as}

\section{a Function of Sintering Temperature}

Xiangyu Wang ${ }^{1 \#}$, En-Cai Xiao ${ }^{2 \# *}$, Lingcui Zhang ${ }^{1 *}$, Yue Xu ${ }^{1}$, Tong Liu ${ }^{1}$, Junzhi Yi ${ }^{1}$, Kaixin Song ${ }^{3}$, Ze-ming $\mathrm{Qi}^{4}$, Feng Shi ${ }^{1,2 *}$

${ }^{1}$ Key Laboratory of Processing and Testing Technology of Glass \& Functional Ceramics of Shandong Province, School of Materials Science and Engineering, Qilu University of Technology (Shandong Academy of Sciences), Jinan, 250353, China

${ }^{2}$ School of Material Science and Engineering, Shandong University of Science and Technology, Qingdao, 266590, China

${ }^{3}$ School of electronics information, Hangzhou Dianzi University, Hangzhou, China ${ }^{4}$ National Synchrotron Radiation Laboratory, University of Science and Technology of China, Hefei, 230029, P.R. China

\#These authors contributed equally to this work and should be considered co-first authors.

*Corresponding author:

Email: sf751106@sina.com.cn (F. Shi), Tel \& Fax.: + 86531 89631227;

983198080@qq.com (E. C. Xiao), Tel \& Fax.: +86 53280691718 ;

zhanglc1982@163.com (L. C. Zhang), Tel \& Fax.: + 86531 89631227;

Abstract: $\mathrm{LiMnPO}_{4}$ (LMP) microwave dielectric ceramics were manufactured at different temperatures via a standard solid-state reaction method, and the LMP ceramic sintered at $750{ }^{\circ} \mathrm{C}$ displayed dielectric properties of $\varepsilon_{r}=7.82, Q \times f=29,189$ $(f=12.7 \mathrm{GHz})$. The lattice vibrational characteristics of LMP ceramics were studied utilizing both infrared reflection and Raman scattering spectroscopy to clarify the basic principle of the dielectric response. The intrinsic properties that were fitted and simulated based on the infrared spectra agreed with the measured property values. The low-frequency vibrational modes contributed more to the dielectric properties than the high-frequency modes. Upon increasing the temperature, the permittivity was positively correlated with the bond length but showed the opposite trend of the Raman shift of mode $9 \operatorname{Ag}\left(v_{1}\right)$. The $Q \times f$ value was positively correlated with the packing 
fraction but negatively correlated with the FWHM of mode $10 \mathrm{Ag}_{\mathrm{g}}\left(\mathrm{v}_{3}\right)$. Thus, the structure-property relationships of LMP ceramics were established as a function of sintering temperature.

Keywords: Microwave dielectric ceramics; Lattice vibrational characteristics; Dielectric properties.

\section{Introduction}

The progress and revolutionary development of modern communication products towards generalization, miniaturization, and high efficiency has increased the requirements and demand for high-performance microwave dielectric ceramics (MWDCs) $)^{1-2}$. Specifically, the substrates used to fabricate integrated circuits must have a low dielectric constant $\left(\varepsilon_{r}\right)$ to reduce signal delays, a high quality factor $(Q \times f)$ to obtain favorable filter characteristics and communication quality, as well as a temperature coefficient of resonance frequency $\left(\tau_{f}\right)$ close to zero to ensure stability. Some MWDCs exhibit excellent dielectric properties, but they require high sintering temperatures and have other shortcomings that severely limit their applications. To save energy and reduce costs, the sintering temperatures of ceramics must be decreased to achieve better sintering characteristics; therefore, MWDCs with low inherent sintering temperatures have attracted attention. ${ }^{1,3-6}$

For lithium-transition metal phosphates $\mathrm{LiRPO}_{4}(\mathrm{R}=\mathrm{Ni}, \mathrm{Mn}, \mathrm{Zn}, \mathrm{Mg})$-series ceramics, ${ }^{7-11}$ different atoms at the $\mathrm{R}$ position affect the crystal structures and inherent properties of the materials. They are generally investigated as cathode materials for lithium-ion batteries and do not display microwave dielectric properties; But some 
scholars have studied the microwave dielectric properties of $\mathrm{LiRPO}_{4}$-series ceramics by adjusting the sintering temperature, doping, substitution, and other methods. So, they have received considerable attention due to their dielectric properties.

For instance, Peng et $a l^{12}$. studied the dielectric properties upon replacing $\mathrm{Zn}^{2+}$ in $\mathrm{LiZnPO}_{4}$ with $\mathrm{Co}^{2+}$ ions, which improved the thermal stability after adding $\mathrm{Pb}_{1.5} \mathrm{Nb}_{2} \mathrm{O}_{6.5}$. When 6 vol.\% $\mathrm{Pb}_{1.5} \mathrm{Nb}_{2} \mathrm{O}_{6.5}$ was added, the $\mathrm{LiZn}_{0.93} \mathrm{Co}_{0.07} \mathrm{PO}_{4}$ ceramic displayed superior properties, including $\varepsilon_{r}=6.09, Q \times f=14,305 \mathrm{GHz}$, and $\tau_{f}=-4.4$ $\mathrm{ppm} /{ }^{\circ} \mathrm{C}$. Xia et $a l^{13}$. adjusted the temperature coefficient of resonant frequency by doping $\mathrm{LiMnPO}_{4}$ ceramics with 19 wt.\% $\quad \mathrm{TiO}_{2}$, which displayed excellent performance $\left(\varepsilon_{r}=12.3, Q \times f=38,671 \mathrm{GHz}\right.$, and $\left.\tau_{f}=6.7 \mathrm{ppm} /{ }^{\circ} \mathrm{C}\right)$ when sintered at $875{ }^{\circ} \mathrm{C}$ for $4 \mathrm{~h}$. The influence of $\mathrm{Zn}^{2+}$ substitution on the microwave dielectric properties of $\mathrm{LiMgPO}_{4}$ ceramics was studied by Thomas et al. ${ }^{14}$, who prepared $\mathrm{LiMg}_{0.9} \mathrm{Zn}_{0.1} \mathrm{PO}_{4}-\mathrm{TiO}_{2}\left(12\right.$ vol.\%) composite ceramics sintered at $950{ }^{\circ} \mathrm{C}$. They displayed dielectric properties of $\varepsilon_{r}=10.1, Q \times f=52,900 \mathrm{GHz}$, and $\tau_{f}=-5 \mathrm{ppm} /{ }^{\circ} \mathrm{C}$.

Few studies have been conducted on the lattice vibrational characteristics of MWDCs, which can be used to interpret their micro-physical mechanisms, i.e., the dielectric response mechanism. Xiao et al. revealed the inherent attributes of $\mathrm{LiNiPO}_{4}$ (LNP) and $\mathrm{LiZnPO}_{4}(\mathrm{LZP})$ ceramics ${ }^{15,16}$, including their intrinsic dielectric properties and the corresponding dielectric response mechanisms, which were affected by the composition, process parameters, and crystal structures of samples. The intrinsic dielectric properties and the dielectric response mechanisms of MWDCs are closely 
related to their lattice vibrational characteristics, which can be studied by using Raman scattering and infrared reflection (IR) spectroscopy.

Compared with LNP and LZP, there is no research on the inherent attributes or the lattice vibrational characteristics of LMP ceramics, which limits the in-depth understanding of these kinds of ceramics. Thus, additional research on LMP ceramics is necessary to articulate their physical dielectric response mechanism. Having a theoretical foundation for lithium-transition metal phosphate $\left(\mathrm{LiRPO}_{4}\right)$-series MWDCs can further promote their engineering applications.

In this work, a conventional solid-state reaction was used to manufacture LMP ceramics at different sintering temperatures. The crystal structures of the LMP ceramics were determined by X-ray diffraction (XRD), and their microstructures were studied by scanning electron microscopy (SEM). The lattice vibrational characteristics were analyzed using Raman and infrared reflection (IR) spectroscopy according to group theory and space group information. The dielectric performances were calculated using the four-parameter semi-quantum (FPSQ) model combined with IR spectroscopy. The structure-property relationships were established using the lattice vibrational modes. The contribution of the vibrational modes to the dielectric properties was determined, which provides a theoretical reference for the design of new MWDCs, especially for controlling their structures and properties.

\section{Experimental}

The LMP ceramics were fabricated using analytically-pure $\mathrm{Li}_{2} \mathrm{CO}_{3}(\mathrm{AR}, \mathrm{Kelon}$ Chemical), $\mathrm{MnCO}_{3}$ (AR, Macklin), and $\mathrm{NH}_{4} \mathrm{H}_{2} \mathrm{PO}_{4}$ (AR, Kelon Chemical) powders 
as raw materials by a conventional solid-state reaction. First, the raw materials were weighed in a stoichiometric ratio and milled with $\mathrm{ZrO}_{2}$ balls in distilled water for $6 \mathrm{~h}$. After drying, the powders were sintered at $600{ }^{\circ} \mathrm{C}$ for $3 \mathrm{~h}$, then ball-milled and dried again. The prepared powders were uniformly mixed with 5 wt.\% polyvinyl alcohol (PVA) solution and pressed into samples under a pressure of $100 \mathrm{MPa}$. The LMP pellets were divided into six parts and sintered at 700, 725, 750, 775, 800, and $825{ }^{\circ} \mathrm{C}$ for $4 \mathrm{~h}$. In addition, the LMP specimens were polished with micron $\mathrm{Al}_{2} \mathrm{O}_{3}$ slurry ahead of all characterization and measurements to form a mirror to reduce the impact of surface defects.

The crystal structures and main phases of the specimens were studied by XRD (Rigaku D/max-2000, Japan) equipped with a $\mathrm{Cu}-\mathrm{K} \alpha$ radiation source in step-and-scan mode. The XRD data were obtained over the diffraction angle range of $10-80^{\circ}$ with a wavelength of $1.542 \AA$, a scanning speed of $4 \%$ min. SEM (Nova-Nano-SEM 450, USA) was used to analyze the microscopic surface topographies of the pellet cross-sections. The Raman scattering spectra were collected by a Raman spectrometer (Lab RAM HR Evolution) with a liquid- $\mathrm{N}_{2}$-cooled device at room temperature. FTIR spectrometry (Bruker Optik $\mathrm{GmbH}$, IFS 66v/s, Germany) was used to gather the infrared reflectivity spectra at room temperature. To collect the far-infrared spectra $\left(50-700 \mathrm{~cm}^{-1}\right)$, a PE-DTGS detector and a Mylar beamsplitter were applied under vacuum, and the mid-infrared (500-4500 $\left.\mathrm{cm}^{-1}\right)$ spectra were obtained by a device composed of a DTGS detector with a Gecoated KBr beamsplitter. 
Archimedes' method was applied to obtain the bulk densities of the LMP samples. The permittivity and quality factors were measured using a network analyzer (E8363B, Agilent Technologies Inc., Palo Alto, CA) via the open-cavity and resonant-cavity methods, respectively.

\section{Results and discussion}

The XRD patterns of the $\mathrm{LiMnPO}_{4}$ (LMP) samples sintered at different temperatures are shown in Figure 1, which were recognized as pure $\mathrm{LiMnPO}_{4}$ phase (JCPDS\#74-0375), belonging to an olivine structure with an orthogonal structure and the Pnmb space group (No. 62). The XRD baselines are flat, and the diffraction peaks are sharp, indicating that all samples have good crystallinity. To further analyze the crystal structures of the LMP ceramics, the XRD data were refined via Rietveld refinement utilizing TOPAS software. The refined lattice parameters of the LMP ceramics are listed in Table 1. The quality of the refined results was characterized by the $R$-factors $\left(R_{w p}, R_{p}\right.$, and $\left.R_{\text {exp }}\right)$, which indicated the reliability and credibility of the refinements. Taking the LMP sample sintered at $750{ }^{\circ} \mathrm{C}$ as an example, the experimental data (pink circle) was consistent with the fitting curve (black curve), as shown in Figure 2, which was demonstrated by the relatively smooth difference curve (green line).

Figure 3 displays the unit cell structure of olivine LMP, which belongs to the orthorhombic crystal system with the Pmnb space group. The unit cell has center symmetry and is composed of four $\mathrm{LiMnPO}_{4}$ molecules with an independent tetrahedral $\left[\mathrm{PO}_{4}\right]^{3-}$ complex formed. The $\mathrm{Li}^{+}$and $\mathrm{Mn}^{2+}$ ions are surrounded by six 
oxygen atoms to form $\left[\mathrm{LiO}_{6}\right]$ and $\left[\mathrm{MnO}_{6}\right]$ octahedra, respectively. The edge of the octahedra encircling the $\mathrm{Li}^{+}$ions is shared by two $\left[\mathrm{PO}_{4}\right]^{3-}$ tetrahedra, but the oxygen octahedra around the $\mathrm{Mn}^{2+}$ ion is shared with only one vertex of the $\left[\mathrm{PO}_{4}\right]^{3-}$ tetrahedron. The crystal's skeleton is formed by sharing edges of [ $\left.\mathrm{LiO}_{6}\right]\left(C_{i}\right.$ symmetry), $\left[\mathrm{MnO}_{6}\right]$ octahedron $\left(C_{s}\right.$ symmetry), and $\left[\mathrm{PO}_{4}\right]^{3-}$ tetrahedron $\left(C_{s}\right.$ symmetry).

Figure 4 shows the variations in the relative density, permittivity, and $Q \times f$ values of LMP ceramics as a function of the sintering temperature. As the sintering temperature increased, these data first increased and then decreased. The dielectric constant reached a minimum at $700{ }^{\circ} \mathrm{C}\left(\varepsilon_{r}=7.63\right)$, the $Q \times f$ value reached the minimum at $825{ }^{\circ} \mathrm{C}(23,556 \mathrm{GHz})$, and the two reached the maximum at $750{ }^{\circ} \mathrm{C}\left(\varepsilon_{r}=\right.$ 7.82, $Q \times f=29,189 \mathrm{GHz}$ ). The LMP ceramic sintered at $750{ }^{\circ} \mathrm{C}$ achieved the highest dielectric properties and also had the highest relative density of $95.90 \%$. Compared with other ceramics, its $Q \times f$ value was better than at a lower sintering temperature.

The surface micromorphology of the LMP ceramics in Figure 5 shows that the pores were gradually sealed upon increasing the sintering temperature. The ceramics displayed a better micromorphology, the relative density gradually increased, and the quality factor also increased progressively. Above $750{ }^{\circ} \mathrm{C}$, the grain boundaries became fuzzy, and abnormal grain growth appeared due to over-sintering, which decreased the quality factor.

Infrared reflectance spectroscopy and room-temperature Raman spectroscopy are used to study the lattice vibrations and intrinsic dielectric properties ${ }^{17-18}$. Based on the group theory analysis, theoretically, 81 optical vibrational modes exist for LMP 
ceramics with the Pmnb space group, whose specific information can be stated as follows: ${ }^{15}$

$$
\begin{aligned}
& \quad \Gamma_{\text {optic }}=11 A_{g}+10 A_{u}+7 B_{1 g}+13 B_{1 u}+11 B_{2 g}+9 B_{2 u}+7 B_{3 g} \\
& +13 B_{3 u}
\end{aligned}
$$

The A and B modes represent a single-degenerate state of symmetric eigenfrequency with respect to the main axis and a single-degenerate state of eigenfrequency with respect to the main axis, respectively. The $g$ represent the central symmetric vibrational mode and the $u$ represent the central antisymmetric vibrational mode. All $\mathrm{Ag}_{\mathrm{g}}$ and $\mathrm{B}_{\mathrm{g}}$ vibrational modes are Raman-active, which are attributed to changes in the polarizability. The infrared-active modes include $13 \mathrm{~B}_{1 \mathrm{u}}, 9 \mathrm{~B}_{2 \mathrm{u}}$, and $13 \mathrm{~B}_{3 \mathrm{u}}$, which are related to vary of the dipole moment. When analyzing the vibrational spectra of phosphates, the vibration (stretching and deformation) of the $\left[\mathrm{PO}_{4}\right]^{3-}$ tetrahedron and the vibration of the $\mathrm{Li}^{+}$and $\mathrm{Mn}^{2+}$ ions are usually considered because the P-O bond is much stronger than the other ionic bonds.

The Raman spectra of the LMP samples at different temperatures are presented in Figure 6. In total, 11 peaks were identified and assigned according to group theory, which allowed them to be classified into two regions: an internal mode with a frequency higher than $400 \mathrm{~cm}^{-1}$ and the external lattice oscillations corresponding to frequencies lower than $400 \mathrm{~cm}^{-1}$. The Raman peak with the strongest intensity appeared at $948 \mathrm{~cm}^{-1}$ (mode 9), assigned as mode $\mathrm{Ag}_{\mathrm{g}}\left(v_{1}\right)$, which represents the symmetric tensile oscillation of the $\left[\mathrm{PO}_{4}\right]^{3-}$ tetrahedron, where each tetrahedron in the unit cell has the same phase ( $\mathrm{A}_{\mathrm{g}}$ symmetry) ${ }^{19}$. The $\mathrm{A}_{\mathrm{g}}$ mode observed around $948 \mathrm{~cm}^{-1}$ 
belongs to the asymmetric symmetric vibration of tetrahedral $\left[\mathrm{PO}_{4}\right]^{3-}$, consistent with a previous report $\left(948.5 \mathrm{~cm}^{-1}\right)^{19}$. It does not include the movement of metal ions due to its symmetry, so the Ag mode of other phosphates has a similar frequency, i.e., 946$950 \mathrm{~cm}^{-1}$ in $\mathrm{LiNiPO}_{4}{ }^{20}$ and $944 \mathrm{~cm}^{-1}$ in $\mathrm{LiCdPO}_{4}{ }^{19}$. The $\mathrm{Ag}_{\mathrm{g}}\left(v_{1}\right)$ mode represents the symmetric tensile vibration of tetrahedral $\left[\mathrm{PO}_{4}\right]^{3-}$, and the $\mathrm{Ag}_{\mathrm{g}}\left(\mathrm{v}_{2}\right)$ mode corresponds to symmetric bending vibrations. The $A_{g}\left(v_{3}\right)$ (mode 10) and $A_{g}\left(v_{4}\right)$ mode (mode 11) are the stretching and bending vibrations of the P-O bond, respectively, and both modes are antisymmetric ${ }^{21}$.

The dielectric constant is affected by pores in the ceramics, which can be corrected according to the porosity $(P)$, and measured permittivity $\left(\varepsilon_{r}\right)$, according to equation (2). The calculation results are summarized in Table 2. ${ }^{15}$

$$
\varepsilon_{r}=\varepsilon_{r c}\left(1-\frac{3 P\left(\varepsilon_{r c}-1\right)}{2 \varepsilon_{r c}+1}\right)
$$

The corrected dielectric constant $\left(\varepsilon_{r c}\right)$ and other properties are summarized in Table 2. As shown in the table, $\varepsilon_{r c}$ and $\varepsilon_{r}$ have opposite trends. $\varepsilon_{r}$ is affected by the ceramics compactness and followed the same trend as the relative density. The relative density was the highest at $750{ }^{\circ} \mathrm{C}$, so $\varepsilon_{r}$ was the largest at this time. $\varepsilon_{r c}$ eliminates the influence of pores, and the crystal structure is the decisive factor. The lower the relative density, the greater the increase in the dielectric constant after correction.

Infrared spectroscopy can be used to study the dielectric response mechanism. The infrared reflection spectrum of LMP fabricated at $750{ }^{\circ} \mathrm{C}$ is shown in Figure 7, where the vibrational modes corresponding to $v_{1}-v_{2}$ are as described above. Within the 
microwave frequency range, the complex dielectric function $\varepsilon^{*}$ and the optical reflectance $R$ satisfy the Fresnel equation (3): ${ }^{22}$

$$
R(\omega)=\left|\frac{\sqrt{\varepsilon^{*}}-1}{\sqrt{\varepsilon^{*}}+1}\right|
$$

The FPSQ model is often performed to infer the corresponding parameters of the oscillator from the infrared reflection spectrum. The equation (4) of the complex dielectric constant related to infrared phonons is as follows: ${ }^{23}$

$$
\varepsilon^{*}(\omega)=\varepsilon^{\prime}(\omega)-i \varepsilon^{\prime \prime}(\omega)=\varepsilon_{\infty} \prod_{j=1}^{n} \frac{\Omega_{j L O}^{2}-\omega^{2}+i \omega \gamma_{j L O}}{\Omega_{j T O}^{2}-\omega^{2}+i \omega \gamma_{j T O}}
$$

where $\varepsilon_{\infty}$ is the optical permittivity caused by high-frequency electron polarization, the number of phonon modes is indicated by $n$, the the $j$-th frequency of transverse and vertical modes are represented by $\Omega_{j T O}$ and $\Omega_{j L O}$, respectively. The damping factor of the transverse and vertical modes are expressed as $\gamma_{j T O}$ and $\gamma_{j L O}$, respectively. The contribution of each infrared vibration mode to the dielectric performance can be calculated by the following formulae: ${ }^{24}$

$$
\varepsilon_{j}=
$$

$$
\frac{\varepsilon_{\infty}}{\Omega_{j T O}^{2}} \frac{\prod_{K=I}\left(\Omega_{k L O}^{2}-\Omega_{j T O}^{2}\right)}{\prod_{K \neq j}\left(\Omega_{k T O}^{2}-\Omega_{j T O}^{2}\right)}
$$

$$
\tan \delta_{j} / \omega=
$$

$$
\frac{\varepsilon_{j} \gamma_{j T O} / \Omega_{j T O}^{2}}{\varepsilon_{\infty}+\prod_{j} \varepsilon_{j}}
$$

The intrinsic dielectric constant and dielectric loss can be obtained by summing the oscillator strength and the loss of all modes, using the following equations: ${ }^{15}$

$$
\varepsilon_{0}=\varepsilon_{\infty}+
$$

$$
\sum_{j=1}^{n} \Delta \varepsilon_{j}
$$




$$
\tan \delta=\sum_{j} \tan \delta_{j}=\sum_{j} \frac{\Delta \varepsilon_{j} \gamma_{j T O}{ }^{\omega}}{\varepsilon_{0} \Omega_{j T O}^{2}}
$$

The detailed simulation results of the LMP samples sintered at $750{ }^{\circ} \mathrm{C}$ are listed in Table 3. The low-frequency vibrational modes have a major contribution to the dielectric properties. The intrinsic dielectric constant value of LMP fitted from the FPSQ model was 7.94, which is close to the measured permittivity of 7.82 and the corrected value $\varepsilon_{r c}$ of 8.23 , which implies that the effect of defective phonon scattering is weak. The simulated dielectric loss was $3.07 \times 10^{-4}$, which is lower than the measured value of $4.36 \times 10^{-4}(f=12.7 \mathrm{GHz})$ because defects on the sample surface will inevitably produce defects in the optical signal. With respect to the permittivity, the dielectric loss is more susceptible to these defects ${ }^{25}$, so the dielectric loss can only be estimated from the IR spectra.

Figures 8 illustrates the relationship between the corrected dielectric constant, the P-O bond length ( in Table 4, calculated using Fullprof software), and a Raman shift of mode 9 upon increasing the sintering temperature. As the temperature increased, the corrected dielectric constants were positively correlated with the P-O bond length, i.e., longer bonds are more easily polarized. This will enhance the dielectric constant, which may indicate that the vibrational frequency of the mode is proportional to its bond energy. The center frequency corresponding to the strongest mode 9 (representing the asymmetric stretching vibration of the P-O tetrahedron) in the LMP Raman diagrams falls and then rises upon increasing the sintering temperature, which is the opposite of the P-O bond length and the corrected dielectric constant trends. The energy of the P-O bond increased and the bond length decreased 
when the vibration frequency increased upon increasing the sintering temperature. Accordingly, a shorter bond length means a larger bond energy (for the same type of valence bond). An inflection point appeared at $750{ }^{\circ} \mathrm{C}$, where the bond length increased at temperatures higher than $750{ }^{\circ} \mathrm{C}$.

The quality factor of ceramics is only related to external factors such as internal stress, pores, impurities, and various defects, as well as to internal factors such as phonons. The packing fraction of ceramics can be calculated by the following formula: $:^{26}$

$$
\begin{aligned}
& \qquad \begin{array}{l}
\text { Packing fraction(\%) } \\
\frac{\text { volume of packed ions }}{\text { volume of unit cell }} \times Z
\end{array}
\end{aligned}
$$

The $Z$ is the number of atomic in the unit cell. As depicted in Figure 9, the quality factor and packing fraction exhibited similar trends. This may be because an increase in the packing fraction weakened lattice vibrations, which increased the quality factor ${ }^{27}$. Changes in the $Q \times f$ value were negatively correlated with the full width at half maximum (FWHM) value of mode 10 (antisymmetric vibration of the tetrahedron $\left[\mathrm{PO}_{4}\right]^{3-}$ ). The FWHM value reflects changes in the degree of order of the crystal structure. Upon changing the P-O bond length, the $\left[\mathrm{PO}_{4}\right]^{3-}$ tetrahedron was distorted, which affected the ordering degree. A lower ordering degree indicates greater damping, which results in a larger dielectric loss, i.e., a lower $Q \times f$ value.

\section{Conclusion}

The feasibility of synthesizing $\mathrm{LiMnPO}_{4}$ ceramics by a solid-state method was studied, and the lattice vibrational characteristics and structure-property relationships 
of LMP samples were analyzed. The prepared pure-phase LMP possessed fine crystallization and clear grain boundaries. Both Raman and IR spectroscopy were obtained to clarify the lattice vibrational characteristics. The Raman and far-infrared modes were also analyzed to investigate the phonon characteristics. IR spectroscopy was used to consider the contribution of each vibrational mode to the dielectric performance in combination with the FPSQ model. The results showed that low-frequency vibrational modes exhibited a greater impact than the high-frequency modes. The relationships between the dielectric properties, FWHM, Raman shifts, as well as the fine structural parameters such as packing fraction, bond length, etc., were determined. The permittivity was positively correlated with the P-O bond length but negatively correlated with the Raman shift of mode 9. As the temperature increased, the $Q \times f$ value was positively correlated with the packing fraction. In contrast, the negative correlation with the FWHM of mode 10 was related to the ordering degree of the P-O tetrahedron. The IR data simulated according to the FPSQ model indicated that the low-frequency vibrational modes have a major contribution to the dielectric properties. LMP sintered at $750{ }^{\circ} \mathrm{C}$ possessed excellent dielectric properties of $\varepsilon_{r}=$ 7.82, $Q \times f=29,189(f=12.7 \mathrm{GHz})$ and the highest relative density of $95.90 \%$.

\section{Acknowledgments}

This work was supported by the National Natural Science Foundation of China (Grant 11874240), the Shandong Provincial Key Research and Development Program, China (No. 2019GGX101060), and Natural Science Foundation of Shandong 
Province (ZR2020QA047). 


\section{Reference}

1. Zhou, D.; Pang, L.-X.; Wang, D.-W.; Li, C.; Jin, B.-B.; Reaney, I. M., High permittivity and low loss microwave dielectrics suitable for $5 \mathrm{G}$ resonators and low temperature co-fired ceramic architecture. J. Mater. Chem. C 2017, 5 (38), 10094-10098.

2. Xiang, H.; Li, C.; Jantunen, H.; Fang, L.; Hill, A., Ultralow loss $\mathrm{CaMgGeO}_{4}$ microwave dielectric ceramic and its chemical compatibility with silver electrodes for low-temperature cofired ceramic applications. Acs Sustainable Chemistry \& Engineering 2018, 6 (5), acssuschemeng.8b00220.

3. Du, X.; Su, H.; Zhang, H.; Liu, X.; Tang, X., Phase evolution and microwave dielectric properties of ceramics with nominal composition $\mathrm{Li}_{2 x}\left(\mathrm{Zn}_{0.95} \mathrm{Co}_{0.05}\right)_{2-x} \mathrm{SiO}_{4}$ for LTCC applications. RSC Advances 2017, 7 (44), 27415-27421.

4. Ren, J.; Bi, K.; Fu, X.; Peng, Z., Novel $\mathrm{Al}_{2} \mathrm{Mo}_{3} \mathrm{O}_{12}$-based temperature-stable MWDCs for LTCC applications. J. Mater. Chem. C 2018, 6 (42), 11465-11470.

5. Zhou, D.; Guo, D.; Li, W. B.; Pang, L. X.; Yao, X.; Wang, D. W.; Reaney, I. M., Novel temperature stable high-epsilon(r) microwave dielectrics in the $\mathrm{Bi}_{2} \mathrm{O}_{3}-\mathrm{TiO}_{2}-\mathrm{V}_{2} \mathrm{O}_{5}$ system. J. Mater. Chem. C 2016, 4 (23), 5357-5362.

6. Zhou, D.; Li, W.-B.; Pang, L.-X.; Guo, J.; Qi, Z.-M.; Shao, T.; Yao, X.; Randall, C. A., Phase evolution and microwave dielectric properties of $x \mathrm{Bi}_{2 / 3} \mathrm{MoO}_{4}-(1-x) \mathrm{BiVO}_{4}(0.0 \leq x \leq 1.0)$ low temperature firing ceramics. Dalton Transactions 2014, 43 (19), 7290-7297.

7. Hu, X.; Cheng, Z. F.; Li, Y.; Ling, Z. Y., Dielectric relaxation and microwave dielectric properties of low temperature sintering $\mathrm{LiMnPO}_{4}$ ceramics. J. Alloy. Compd. 2015, 651, 290-293.

8. Xia, C. C.; Jiang, D. H.; Chen, G. H.; Luo, Y.; Li, B.; Yuan, C. L.; Zhou, C. R., Microwave dielectric ceramic of $\mathrm{LiZnPO}_{4}$ for LTCC applications. Journal of Materials Science: Materials in Electronics 2017, 28 (16), 12026-12031.

9. Zhang, P.; Sun, K. X.; Wu, S. X.; Xiao, M., Microwave dielectric properties of low temperature co-fired ceramics $\mathrm{LiMg}_{1-x} \mathrm{~A}_{x} \mathrm{PO}_{4}(\mathrm{~A}=\mathrm{Mn}, \mathrm{Ca}, 0.02 \leq x \leq 0.08)$. Mater. Lett. 2019, 255, 5.

10. Zhang, P.; Wu, S. X.; Xiao, M., The microwave dielectric properties and crystal structure of low temperature sintering $\mathrm{LiNiPO}_{4}$ ceramics. J. Eur. Ceram. Soc. 2018, 38 (13), 4433-4439.

11. Peng, R.; Lu, Y.; Tao, Z.; Chen, D.; Shi, L.; Zhang, Q.; Li, Y., Improved microwave dielectric properties and sintering behavior of $\mathrm{LiZnPO}_{4}$ ceramic by $\mathrm{Ni}^{2+}$-ion doping based on first-principle calculation and experiment. Ceramics International 2020.

12. Peng, R.; Li, Y. X.; Yu, G. L.; Lu, Y. C.; Li, S., Effect of $\mathrm{Co}^{2+}$ Substitution on the Microwave Dielectric Properties of $\mathrm{LiZnPO}_{4}$ Ceramics. J. Electron. Mater. 2018, 47 (12), 7281-7287.

13. Xia, C. C.; Chen, G. H.; Yuan, C. L.; Zhou, C. R., Low-temperature co-fired $\mathrm{LiMnPO}_{4}-\mathrm{TiO}_{2}$ ceramics with near-zero temperature coefficient of resonant frequency. Journal of Materials Science: Materials in Electronics 2017, 28 (18), 13970-13975.

14. Thomas, D.; Sebastian, M. T., Effect of $\mathrm{Zn}^{2+}$ substitution on the microwave dielectric properties of $\mathrm{LiMgPO}_{4}$ and the development of a new temperature stable glass free LTCC. J. Eur. Ceram. Soc. 2012, 32 (10), 2359-2364.

15. Xiao, E. c.; Cao, Z.; Li, J.; Li, X. H.; Liu, M.; Yue, Z.; Chen, Y.; Chen, G.; Song, K.; Zhou, H.; Shi, F., Crystal structure, dielectric properties, and lattice vibrational characteristics of $\mathrm{LiNiPO}_{4}$ ceramics sintered at different temperatures. Journal of the American Ceramic Society 2019, 103 (4), 2528-2539.

16. Feng Shi, En-Cai Xiao*, Sintering behavior, crystal structures, phonon characteristics and 
dielectric properties of LiZnPO4 MWDCs, Materials Chemistry and Physics, 2021, 259(1):124139.

17. Baddour-Hadjean, R.; Pereira-Ramos, J.-P., Raman Microspectrometry Applied to the Study of Electrode Materials for Lithium Batteries. Chemical Reviews 2010, 110 (3), 1278-1319.

18. Pang, L.-X.; Zhou, D.; Qi, Z.-M.; Liu, W.-G.; Yue, Z.-X.; Reaney, I. M., Structure-property relationships of low sintering temperature scheelite-structured $(1-x) \mathrm{BiVO}_{4}-x \mathrm{LaNbO}_{4}$ MWDCs. $J$. Mater. Chem. C 2017, 5 (10), 2695-2701.

19. Paques-Ledent, M. T.; Tarte, P., Vibrational studies of olivine-type compounds-I. The i.r. and Raman spectra of the isotopic species of $\mathrm{Mg}_{2} \mathrm{SiO}_{4}$. Spectrochimica Acta Part A: Molecular Spectroscopy 1973, 29 (6), 1007-1016.

20. Chung, S. Y.; Bloking, J. T.; Chiang, Y. M., Electronically conductive phospho-olivines as lithium storage electrodes. Nat. Mater. 2002, 1 (2), 123-128.

21. Korona, K. P.; Papierska, J.; Kaminska, M.; Witowski, A.; Michalska, M.; Lipinska, L., Raman measurements of temperature dependencies of phonons in $\mathrm{LiMnPO}_{4}$. Materials Chemistry and Physics 2011, 127 (1-2), 391-396.

22. Xiao, E.-C.; Li, J.; Wang, J.; Xing, C.; Guo, M.; Qiao, H.; Wang, Q.; Qi, Z.-M.; Dou, G.; Shi, F., Phonon characteristics and dielectric properties of $\mathrm{BaMoO}_{4}$ ceramic. Journal of Materiomics 2018, 4 (4), 383-389.

23. Xing, C.; Li, J. Z.; Wang, J.; Chen, H. L.; Qiao, H. Y.; Yin, X. Q.; Wang, Q.; Qi, Z. M.; Shi, F., Internal Relations between Crystal Structures and Intrinsic Properties of Nonstoichiometric $\mathrm{Ba}_{1+x} \mathrm{MoO}_{4}$ Ceramics. Inorg. Chem. 2018, 57 (12), 7121-7128.

24. Li, J. Z.; Wang, J.; Fu, G. G.; Xing, C.; Yin, X. D.; Qiao, H. Y.; Chen, H. F.; Qi, Z. M.; Wang, Q.; Shi, F., Crystal structure characteristics, intrinsic properties, and vibrational spectra of non-stoichiometric $\mathrm{Ca}_{1+x} \mathrm{WO}_{4}$ ceramics. J. Appl. Phys. 2018, 124 (4), 10.

25. Petzelt, J.; Kamba, S., Submillimetre and infrared response of microwave materials: extrapolation to microwave properties. Materials Chemistry and Physics 2003, 79 (2), 175-180.

26. Kim, E. S.; Chun, B. S.; Freer, R.; Cernik, R. J., Effects of packing fraction and bond valence on microwave dielectric properties of $\mathrm{A}^{2+} \mathrm{B}^{6+} \mathrm{O}_{4}\left(\mathrm{~A}^{2+}\right.$ : $\mathrm{Ca}, \mathrm{Pb}, \mathrm{Ba}$; $\mathrm{B}^{6+}$ : Mo, W) ceramics. J. Eur. Ceram. Soc. 2010, 30 (7), 1731-1736.

27. Kim, E. S.; Kim, S. H., Effects of structural characteristics on microwave dielectric properties of $(1-x) \mathrm{CaWO}_{4}-x \mathrm{LaNbO}_{4}$ ceramics. Journal of Electroceramics 2006, 17 (2), 471-477. 


\section{Table and Figure captions}

Table 1. Crystallographic data of $\mathrm{LiMnPO}_{4}$ ceramics derived from the Rietveld refinement of XRD data.

Table 2. The bond lengths of $\mathrm{LiMnPO}_{4}$ ceramics.

Table 3. Fitting parameters of the infrared reflectivity spectrum of $\mathrm{LiMnPO}_{4}$ ceramics.

Table 4. The permittivity and the corrected permittivity of $\mathrm{LiMnPO}_{4}$ ceramics.

Figure 1. XRD patterns of $\mathrm{LiMnPO}_{4}$ ceramics sintered at different temperatures for $4 \mathrm{~h}$.

Figure 2. XRD refinement image of $\mathrm{LiMnPO}_{4}$ ceramics (the pink circle is the experimental data; the black curve is the refined data; the green line below the image is the difference profile).

Figure 3. Unit cell representation of $\mathrm{LiMnPO}_{4}$ ceramic.

Figure 4. Relationship between the relative density, permittivity, and $Q \times f$ value as a function of sintering temperature.

Figure 5. SEM micrographs of $\mathrm{LiMnPO}_{4}$ ceramics.

Figure 6. Raman spectra of $\mathrm{LiMnPO}_{4}$ ceramics.

Figure 7. Collected and fitted IR spectrum of $\mathrm{LiMnPO}_{4}$ ceramics.

Figure 8. Relationship between the corrected dielectric constant $\varepsilon_{r c}$, P-O bond length, and Raman shift of mode 9 as a function of sintering temperature.

Figure 9. Relationship between the $Q \times f$ value, FWHM of mode 10, and packing fraction as a function of sintering temperature. 
Table 1. Crystallographic data of $\mathrm{LiMnPO}_{4}$ ceramics derived from the Rietveld refinement of the XRD data.

\begin{tabular}{|c|c|c|c|c|c|c|c|}
\hline Sample & LMP-700 & LMP-725 & LMP-750 & LMP-775 & LMP-800 & LMP-825 & $\begin{array}{l}\text { Standard } \\
\text { deviation }\end{array}$ \\
\hline$a(\AA)$ & 6.1398 & 6.1107 & 6.1523 & 6.0648 & 6.1328 & 6.1372 & 0.0288 \\
\hline$b(\AA)$ & 10.4250 & 10.4592 & 10.0408 & 10.4101 & 10.4451 & 10.4540 & 0.1492 \\
\hline$c(\AA)$ & 4.7882 & 4.7479 & 4.8513 & 4.7859 & 4.7781 & 4.7847 & 0.0308 \\
\hline$\alpha=\beta=\gamma\left({ }^{\circ}\right)$ & 90 & 90 & 90 & 90 & 90 & 90 & \\
\hline$V\left(\AA^{3}\right)$ & 306.4787 & 303.4507 & 299.6831 & 302.1561 & 306.0766 & 306.9769 & 2.6313 \\
\hline$\rho\left(\mathrm{g} / \mathrm{cm}^{3}\right)$ & 3.399 & 3.433 & 3.476 & 3.448 & 3.404 & 3.394 & 0.0296 \\
\hline $\begin{array}{l}\text { Packing } \\
\text { fraction } \\
(\%)\end{array}$ & 65.83 & 66.49 & 67.32 & 66.77 & 65.92 & 65.72 & 0.5757 \\
\hline \multicolumn{8}{|l|}{$R$-factor } \\
\hline$R_{w p}$ & 12.12 & 12.04 & 12.31 & 12.89 & 13.16 & 13.12 & \\
\hline$R_{p}$ & 7.73 & 7.69 & 8.08 & 8.64 & 9.07 & 8.64 & \\
\hline$R_{e x p}$ & 10.23 & 10.61 & 10.45 & 10.53 & 10.30 & 10.59 & \\
\hline GOF & 1.18 & 1.13 & 1.18 & 1.22 & 1.28 & 1.24 & \\
\hline
\end{tabular}


Table 2. The permittivity and the corrected permittivity of $\mathrm{LiMnPO}_{4}$ ceramics.

\begin{tabular}{cccccc}
\hline \hline Temperature & $\varepsilon_{r}$ & $\varepsilon_{r c}$ & $Q \times f$ & $\begin{array}{c}\text { Density } \\
\left(\mathrm{g} / \mathrm{cm}^{3}\right)\end{array}$ & $\begin{array}{c}\text { Relative } \\
\text { density (\%) }\end{array}$ \\
\hline 700 & 7.63 & 8.29 & 27,288 & 3.399 & 93.53 \\
725 & 7.74 & 8.27 & 28,564 & 3.433 & 94.90 \\
750 & 7.82 & 8.23 & 29,189 & 3.476 & 95.90 \\
775 & 7.75 & 8.25 & 26,237 & 3.448 & 95.20 \\
800 & 7.74 & 8.26 & 25,084 & 3.404 & 94.98 \\
825 & 7.71 & 8.27 & 23,556 & 3.394 & 94.58 \\
\hline \hline
\end{tabular}


Table 3. Fitting parameters of the infrared reflectivity spectrum of $\mathrm{LiMnPO}_{4}$ ceramics.

\begin{tabular}{ccccccc}
\hline \hline Mode & $\begin{array}{c}\Omega_{j T O} \\
\left(\mathrm{~cm}^{-1}\right)\end{array}$ & $\begin{array}{c}\gamma_{j T O} \\
\left(\mathrm{~cm}^{-1}\right)\end{array}$ & $\begin{array}{c}\Omega_{j L O} \\
\left(\mathrm{~cm}^{-1}\right)\end{array}$ & $\begin{array}{c}\gamma_{j L O} \\
\left(\mathrm{~cm}^{-1}\right)\end{array}$ & $\Delta \varepsilon_{j}$ & $\begin{array}{c}\tan \delta_{j / \omega} \\
\left(\times 10^{-5}\right)\end{array}$ \\
\hline 1 & 133.40 & 6.79 & 134.57 & 7.37 & 0.1998 & 0.9599 \\
2 & 169.06 & 16.55 & 173.01 & 12.67 & 0.8671 & 6.3210 \\
3 & 181.08 & 17.50 & 193.07 & 22.60 & 0.9071 & 6.0939 \\
4 & 233.42 & 18.02 & 252.49 & 18.43 & 1.1664 & 4.8570 \\
5 & 297.32 & 62.62 & 312.30 & 21.64 & 1.0982 & 9.7926 \\
6 & 319.11 & 25.35 & 333.66 & 18.48 & 0.3643 & 1.1415 \\
7 & 335.44 & 16.49 & 353.68 & 31.25 & 0.0604 & 0.1114 \\
8 & 360.51 & 33.57 & 390.13 & 75.38 & 0.0962 & 0.3129 \\
9 & 452.22 & 35.85 & 474.40 & 36.87 & 0.2435 & 0.5372 \\
10 & 480.63 & 28.98 & 492.98 & 60.06 & 0.0253 & 0.0400 \\
11 & 516.02 & 27.19 & 517.62 & 33.44 & 0.0076 & 0.0097 \\
12 & 549.36 & 19.02 & 557.46 & 19.57 & 0.0478 & 0.0379 \\
13 & 587.44 & 35.23 & 589.89 & 22.38 & 0.0141 & 0.0181 \\
14 & 635.62 & 17.24 & 646.48 & 13.52 & 0.0615 & 0.0331 \\
15 & 973.43 & 43.46 & 986.46 & 50.89 & 0.1295 & 0.0747 \\
16 & 1001.08 & 32.93 & 1003.79 & 39.35 & 0.0170 & 0.0070 \\
17 & 1043.40 & 136.80 & 1083.24 & 21.44 & 0.2263 & 0.3579 \\
18 & 1091.12 & 23.73 & 1117.36 & 24.96 & 0.0199 & 0.0050 \\
19 & 1138.47 & 32.84 & 1154.22 & 26.81 & 0.0143 & 0.0046 \\
Sum & & & & & 5.5664 & 30.7153 \\
\hline \hline
\end{tabular}


Table 4. The bond lengths of $\mathrm{LiMnPO}_{4}$ ceramics.

\begin{tabular}{cccccccc}
\hline $\begin{array}{c}\text { Bond length } \\
(\AA)\end{array}$ & LMP-700 & LMP-725 & LMP-750 & LMP-775 & LMP-800 & LMP-825 & $\begin{array}{c}\text { Standard } \\
\text { deviation }\end{array}$ \\
\hline $\mathrm{Li}-\mathrm{O}(1) \times 2$ & 2.2364 & 2.2268 & 2.2317 & 2.2226 & 2.2346 & 2.2367 & 0.0051 \\
$\mathrm{Li}-\mathrm{O}(2) \times 2$ & 2.1283 & 2.1156 & 2.1392 & 2.1142 & 2.1253 & 2.1274 & 0.0084 \\
$\mathrm{Li}-\mathrm{O}(3) \times 2$ & 2.1629 & 2.1601 & 2.1265 & 2.1601 & 2.1636 & 2.1659 & 0.0135 \\
$\mathrm{~d}_{\text {ave }}$ & 2.1759 & 2.1675 & 2.1658 & 2.1656 & 2.1745 & 2.1767 & 0.0047 \\
$\mathrm{Mn}-\mathrm{O}(1) \times 1$ & 2.2400 & 2.2406 & 2.1871 & 2.2373 & 2.2420 & 2.2442 & 0.0201 \\
$\mathrm{Mn}-\mathrm{O}(2) \times 1$ & 2.1392 & 2.1393 & 2.0906 & 2.1367 & 2.1409 & 2.1430 & 0.0184 \\
$\mathrm{Mn}-\mathrm{O}(3) \times 2$ & 2.1433 & 2.1330 & 2.1458 & 2.1237 & 2.1410 & 2.1428 & 0.0076 \\
$\mathrm{Mn}-\mathrm{O}(3) \times 2$ & 2.2925 & 2.2838 & 2.2812 & 2.2830 & 2.2911 & 2.2934 & 0.0049 \\
$\mathrm{~d}_{\text {ave }}$ & 2.2038 & 2.1992 & 2.1762 & 2.1952 & 2.2038 & 2.2059 & 0.0100 \\
$\mathrm{P}-\mathrm{O}(1) \times 1$ & 1.5593 & 1.5462 & 1.5797 & 1.5585 & 1.5560 & 1.5581 & 0.0100 \\
$\mathrm{P}-\mathrm{O}(2) \times 1$ & 1.5236 & 1.5263 & 1.4777 & 1.5216 & 1.5257 & 1.5271 & 0.0176 \\
$\mathrm{P}-\mathrm{O}(3) \times 2$ & 1.5553 & 1.5496 & 1.5487 & 1.5428 & 1.5543 & 1.5556 & 0.0045 \\
$\mathrm{~d}_{\text {ave }}$ & 1.5461 & 1.5407 & 1.5354 & 1.5410 & 1.5453 & 1.5469 & 0.0040 \\
\hline \hline
\end{tabular}




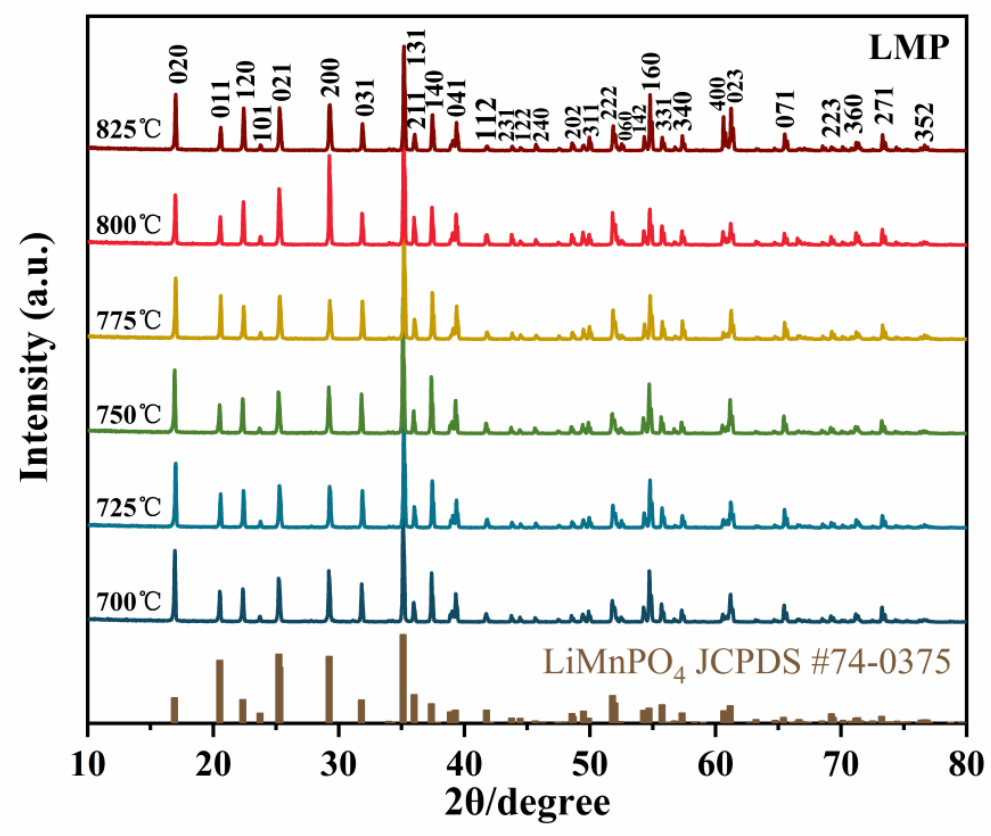

Figure 1. XRD patterns of $\mathrm{LiMnPO}_{4}$ ceramics sintered at different temperatures for $4 \mathrm{~h}$. 


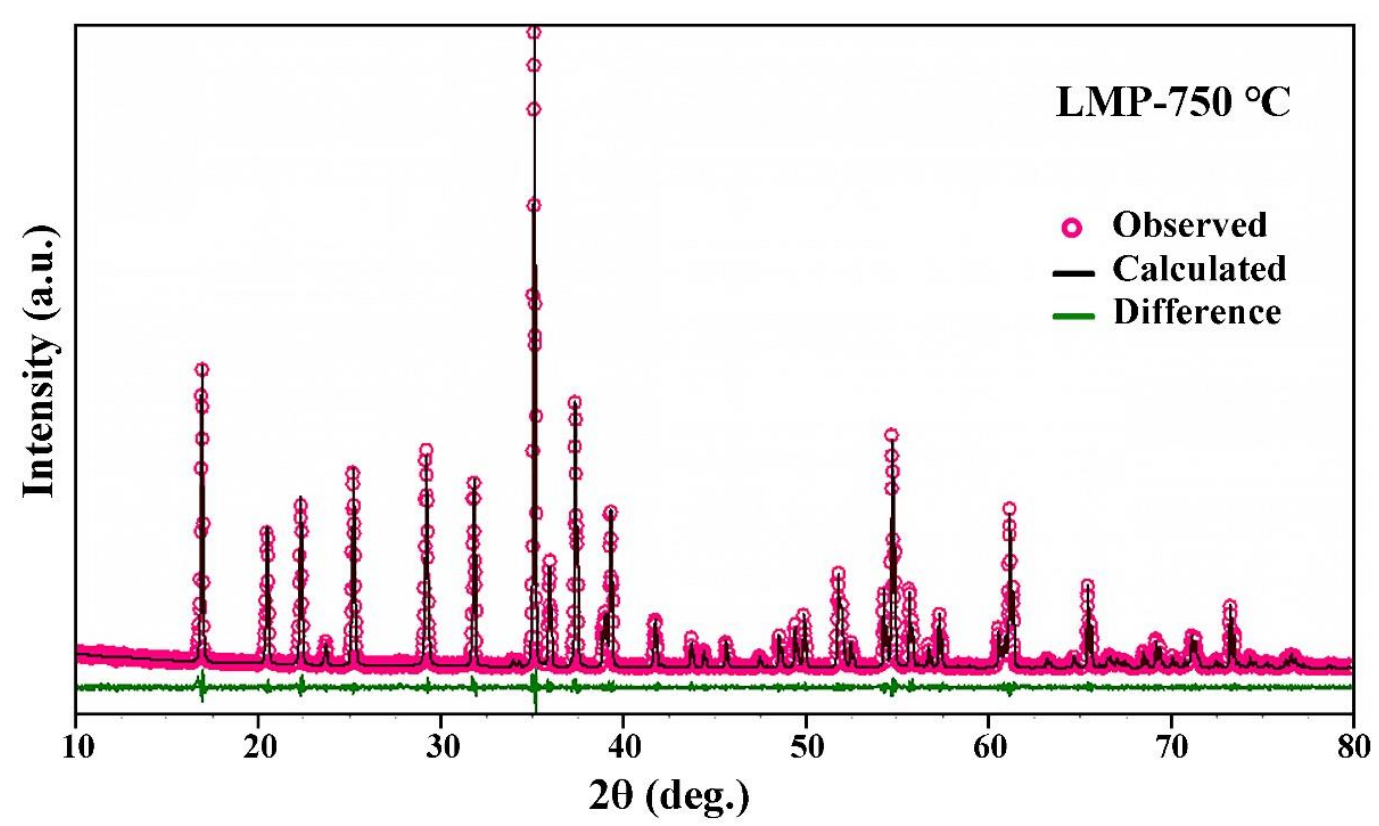

Figure 2. XRD refinement of $\mathrm{LiMnPO}_{4}$ ceramics (the pink circle is the experimental data; the black curve is the refined data; the green line below the image is the difference profile). 


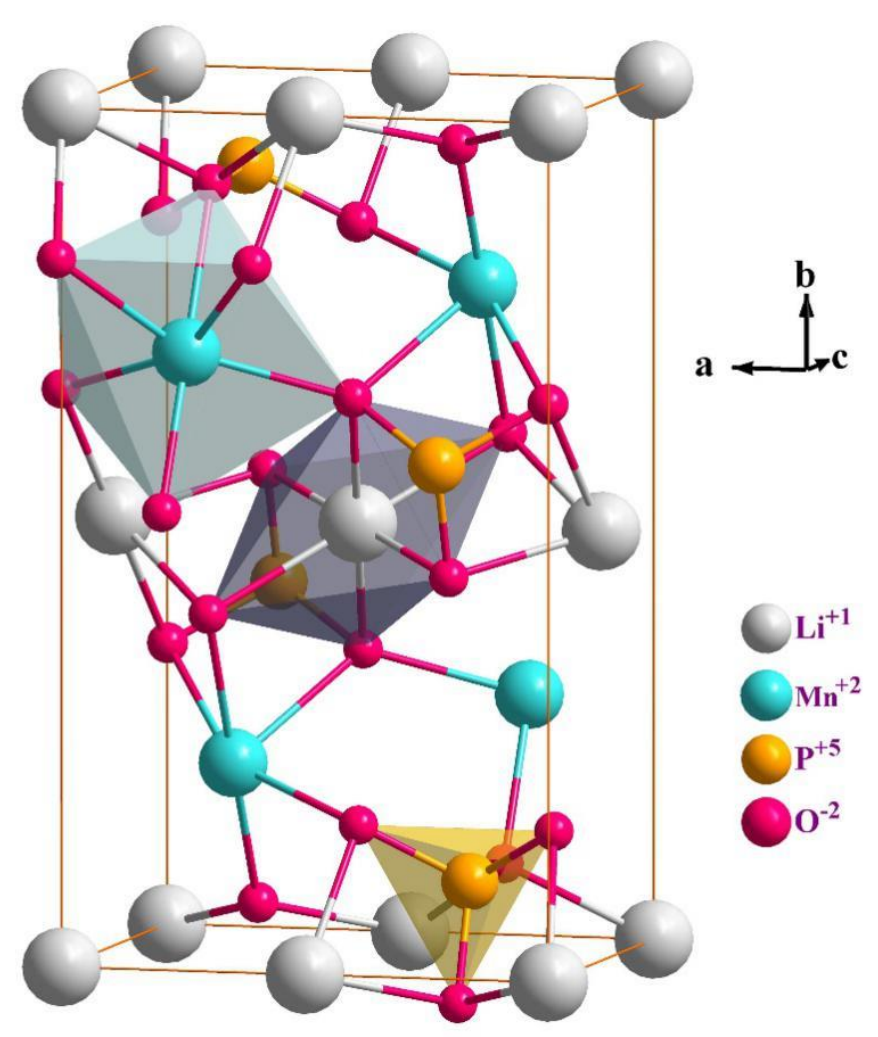

LMP

Figure 3. Unit cell representation of $\mathrm{LiMnPO}_{4}$ ceramic. 


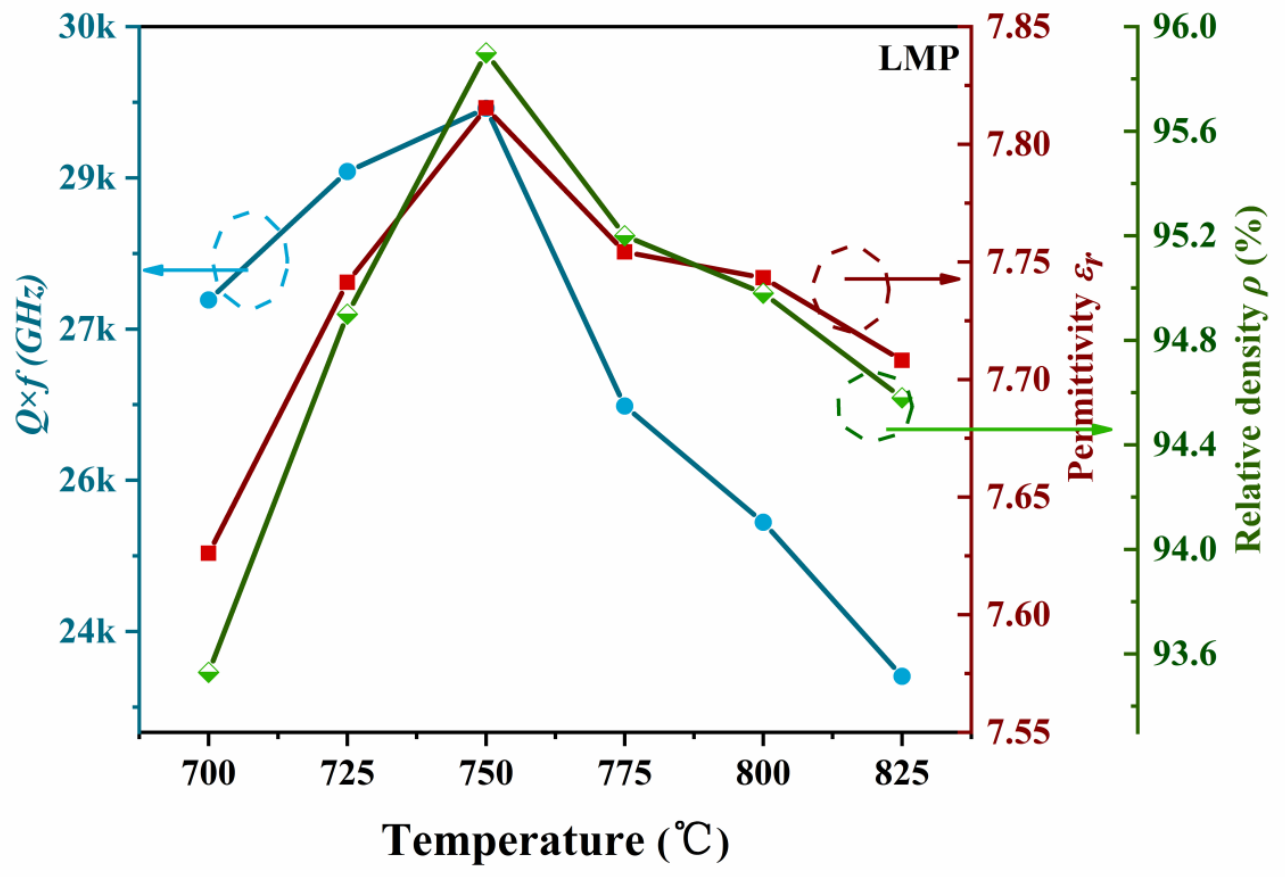

Figure 4. Relationship between the relative density, permittivity, and $Q \times f$ value, as a function of sintering temperature. 

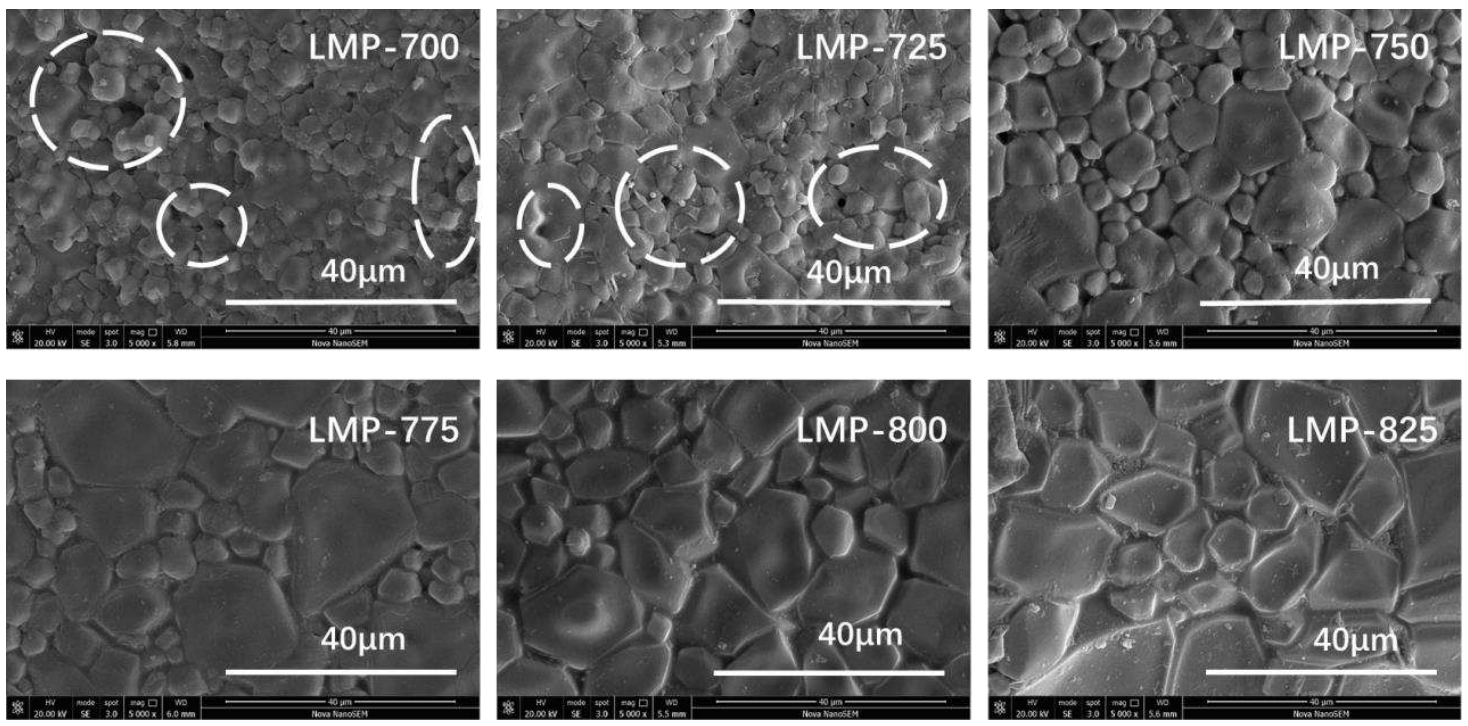

Figure 5. SEM micrographs of $\mathrm{LiMnPO}_{4}$ ceramics. 


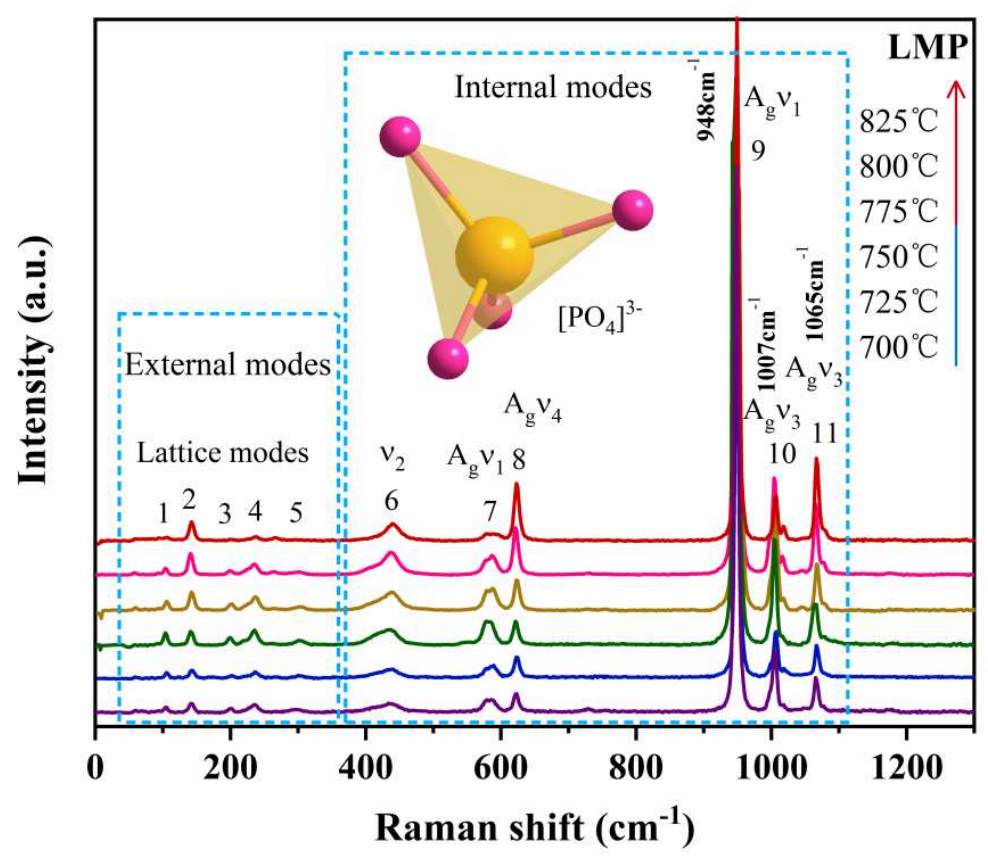

Figure 6. Raman spectra of $\mathrm{LiMnPO}_{4}$ ceramics. 


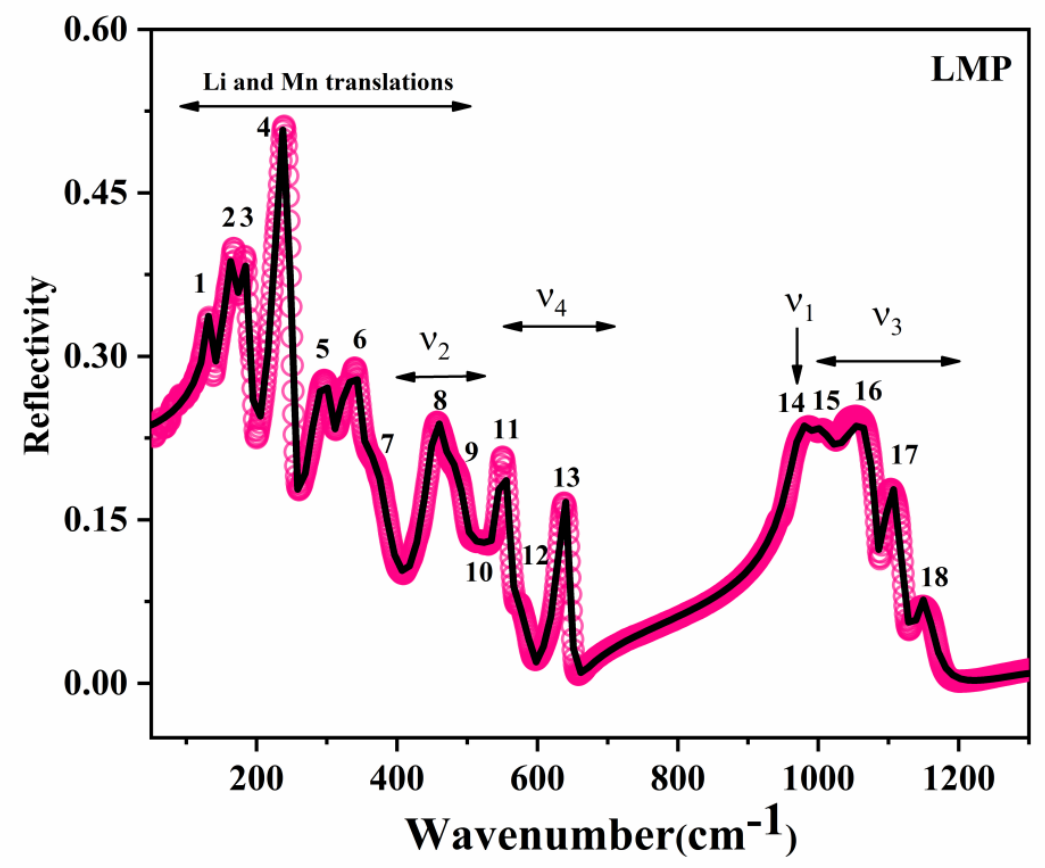

Figure 7. Collected and fitted IR spectra of $\mathrm{LiMnPO}_{4}$ ceramic sintered at $750{ }^{\circ} \mathrm{C}$. 


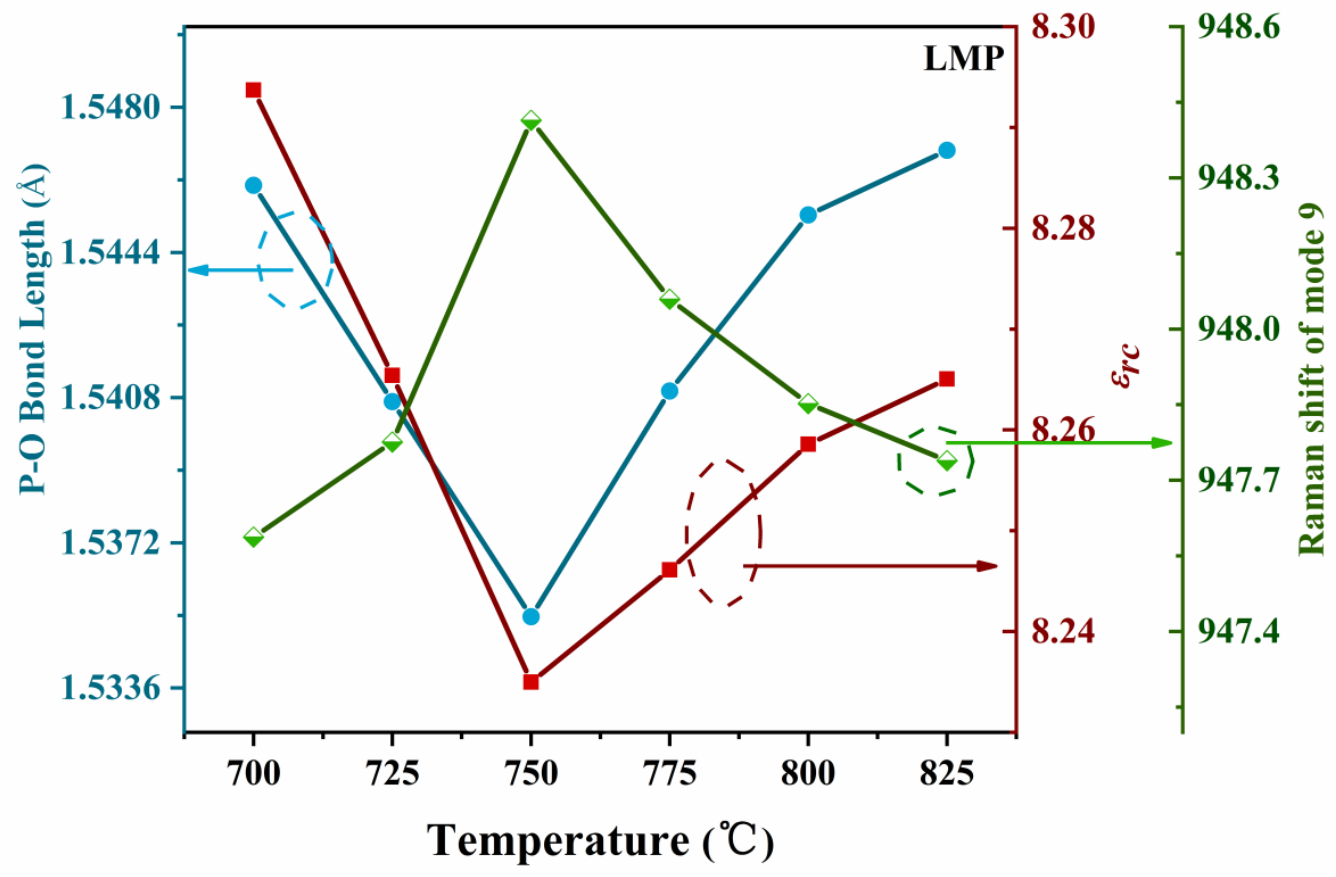

Figure 8. Relationship between the corrected dielectric constant $\varepsilon_{r c}$, P-O bond length, and Raman shift of mode 9 as a function of temperature. 


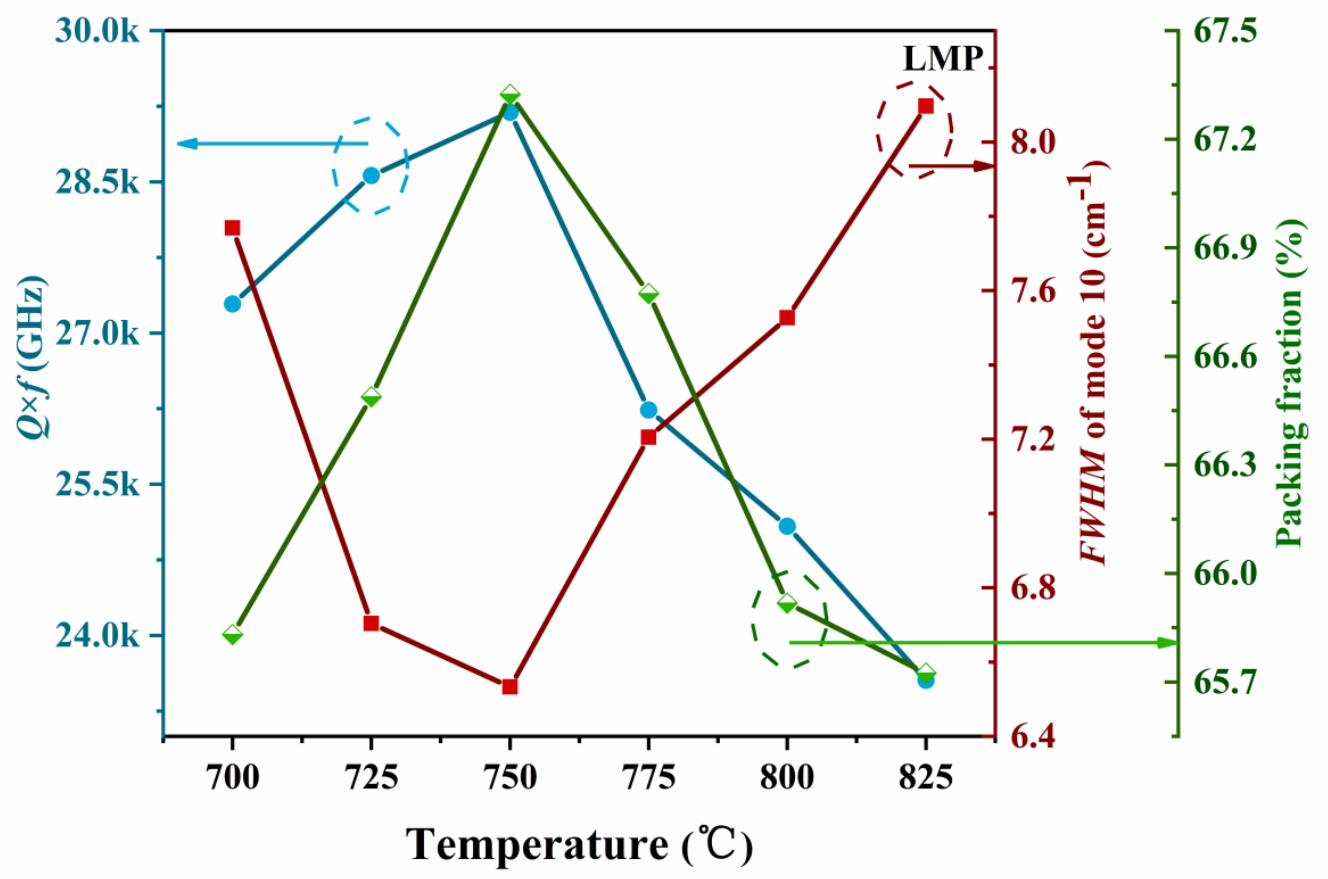

Figure 9. Relationship between the $Q \times f$ value, FWHM of mode 10, and packing fraction as a function of sintering temperature. 